\title{
La inasibilidad de lo real: el ciervo huidizo de la identidad
}

\section{The Inaccessibility of Truth: The Elusive Deer of Identity}

\author{
Lola Proaño Gómez \\ Pasadena City College, Languages Division. California, EE.UU \\ lolaproanio@aol.com
}

Resumen: Este artículo responde a la pregunta por la posibilidad de una lectura política de los productos teatrales latinoamericanos de los últimos años, enfatizando la presencia de «lo político» en forma de rupturas lógicas y de sentido que dislocan el escenario teatral desde adentro. El grupo cubano El Ciervo Encantado, (2005-2008) busca - según el programa de mano- encontrar en Visiones de la cubanosofía, «ese ciervo escurridizo que es la identidad». La escena despliega, mediante múltiples técnicas teatrales, la incapacidad del lenguaje - lo simbólicopara captarla. La propuesta escenifica lo que se niega: la imposibilidad de aprehender la identidad exhibiendo sólo las sucesivas identificaciones que no la alcanzan. La escena señala que ellas han sido solamente un espejismo, resultado del reflejo de los discursos culturales producidos a través de la historia.

Palabras clave: Lo político; lenguaje; identidad, Cuba, identificaciones.

Abstract: This article is an answer to the question on the possibility of a political interpretation of recent Latin American dramatic products, emphasising on «political issues» through meaningful and logical ruptures that dislocate the stage from within. The Cuban theatre troupe El Ciervo Encantado (2005-2008), based on its programme, aims to find in Visiones de la cubanosofía, "the elusive deer that is identity». On stage is displayed, through various theatrical techniques, the incapacity of language - its symbolic aspect - to capture it. The proposal stages what is denied: the impossibility to apprehend identity by only presenting the successive identifications that cannot reach it. The scene states that it has only been an illusion caused by the reflection of the cultural discourses created through history.

Keywords: Political issues; language; identity; Cuba; identifications. 
Artistic creation is not limited within fantasy and political invention is not limited within utopian politics.

(Starvakakis, 2005:132)

Este artículo ${ }^{1}$ sigue la línea de una investigación que se pregunta por la posibilidad de una lectura política de los productos teatrales latinoamericanos de los últimos años. ${ }^{2} \mathrm{Me}$ interesan en especial aquellos textos que no tratan explícitamente aspectos de la política, y que, sin tener una coherencia narrativa evidente, generan un clima escénico mediante procedimientos y técnicas particulares, que transmiten al espectador sensaciones que lo disparan a un ámbito de la realidad difícil de expresar en el lenguaje y lo llevan a preguntarse acerca de su rol en el presente y en el futuro. Esto es el efecto, muchas veces logrado de modo más sensorial que intelectual de la presencia de «lo político» como un sustrato común a la escena latinoamericana de fin de siglo.

Es importante diferenciar de la manera más clara posible «lo político» de la política, puesto que este último concepto de las ciencia políticas - tomado de Jacques Ranciere (2001) - exige una comprensión no tradicional, diferente de lo que se ha entendido como «teatro político». Propongo entonces entender la política como la lucha o el enfrentamiento de intereses y el accionar de los individuos en la polis, dentro de un sistema de normas instituidas. La política es, en este sentido, el ejercicio de la «profesión» en los límites institucionales definidos por el espacio estático del Estado jurídico; es la lucha por el poder interno de la polis o la lucha entre dos órdenes diversos y contrapuestos; es la profesión, el saber de los políticos o filósofos.

Lo político tiene varias notas que lo caracterizan. Respecto del presente trabajo, interesa su presencia como un momento de apertura e indecibilidad, su emergencia en la escena en la intersección de acciones y lógicas como un momento de interrupción y una ruptura de sentido, que no queda confinado en las prácticas aceptadas y que implica poner en cuestión los principios estructurales del orden establecido (Proaño, 2007: 8-9); es también una instancia antropológicamente originaria y socialmente fundacional; el espacio de una ontología práctica, la búsqueda del sentido del «ser» en su existencia concreta en la praxis. Todo ello presente en Visiones de la cubanosofía, el espectáculo que esta vez nos ocupa.

Este espectáculo ejemplifica la escena latinoamericana en tanto presenta el conflicto entre la articulación simbólica teatral y el «afuera» o el «más allá del lenguaje» que no puede terminar de expresarse, lo que genera una tensión en la que el espectador apenas vislumbra lo que se intenta enunciar. ${ }^{3}$

\footnotetext{
Agradezco a Iliana Dieguez y Nara Mansur por su lectura y sus sugerencias.

2 Al respecto ver Poéticas de la globalización en el teatro latinoamericano (Proaño-Gómez).

3 Son muchos y variados los espectáculos latinoamericanos en los que esta característica está presente: No me toquen ese vals (Perú, Yuyachkani), Máquina Hamlet (Argentina, El Periférico de los Objetos, Crápula Mácula (Colombia, el Barco Ebrio), La razón blindada (Ecuador, Malayerba) y Borges (Argentina, Cero Grupo Teatro) entre otros muchos.
} 
Visiones de la cubanosofía del grupo teatral El Ciervo Encantado, ${ }^{4}$ fundado en La Habana, en 1996, fue estrenada en abril de 2005,5 como parte del ritual de la memoria. El grupo creado a partir de la experiencia pedagógica desarrollada por Nelda Castillo en el Instituto Superior de Arte cubano (ISA), se caracteriza por su interés en los procesos investigativos y por la creación de un lenguaje propio que le permite acceder a un modo especial de expresión teatral que destaca el universo visual y sonoro. El grupo cubano utiliza fuentes literarias, plásticas, musicales y de danza; explora la identidad cultural cubana y tiene como fuentes textos de Alfonso Bernal del Riesgo, Fernando Ortiz, José Martí, Severo Sarduy, Reinaldo Arenas, Lorelis Amores, Julio Alexis Torres y Virgilio Piñera. Estas fuentes de investigación se manifiestan incluso en el nombre del grupo que es una adaptación de dos títulos clásicos de la literatura cubana. ${ }^{6}$

Nos acercamos entonces a Visiones de la cubanosofía con el propósito de decodificar su sentido leyendo la producción como una cadena de significantes que esbozan un significado a través de los agujeros que aparecen en la escena.

\section{A LA CAZA DEL «CIERVO ESCURRIDIZO»}

El espectáculo cubano plantea una exploración que, tal como se afirma en el programa de mano de la función realizada en el Ista en Mayo del 2006: es «la cacería de ese ciervo escurridizo y mágico que es nuestra identidad... Nuestra posibilidad de saber». No se habla aquí de críticas a sistemas o prácticas institucionales, sino que se trata de intentar aprehender, mediante el lenguaje teatral, aquello que está más allá de él y de la escena, de aprehender la «esencia» del ser cubano - aquello más allá de la construcción simbólica de la realidad-, se busca lo que conforma su identidad.

El Ciervo Encantado parece estar consciente de los límites del lenguaje y los símbolos, puesto que al buscar respuesta a la pregunta fundamental que se plantea, la escena problematiza su representabilidad, a pesar de lo cual insiste en la necesidad de seguir interrogándose en el espacio teatral. Por ello, en la escenificación de la búsqueda, el espectáculo muestra de modo simultáneo y contradictorio la indagación y su fracaso.

La construcción simbólica articula una realidad teatral y política y des-construye las identificaciones que en la historia han intentado representar la cubanidad: hay entonces un esfuerzo - condenado al fracaso desde el vamos - de traspasar el ámbito del lenguaje que construye la realidad escénica, para tratar de capturar o al menos esbozar aquello que la palabra es incapaz de expresar: la identidad cubana que, por corresponder al ámbito de lo real, en tanto situada fuera de la construcción lingüístico-simbólica, es imposible

\footnotetext{
4 Premio Villanueva de la crítica especializada, 2005. Premio Adolfo Llaurado a Lorelis Amores. Mejor actuación femenina Teatro Dramático 2005. Invitada al Mayo Teatral, La Habana, Cuba, 2008.

5 Este artículo trabaja con una versión del manuscrito no publicada.

6 Según Rafael de Aguila, El ciervo encantado (1905) título del primer libro de cuentos de la literatura cubana, escrito por Esteban Borrero, oficial del Ejército Libertador y La cubanosofía, fundamento de la educación cívica nacional de Alfonso Bernal del Riesgo, miembro fundador del primer Partido Comunista de Cuba, se juntan en el nombre del grupo y el título de la obra que «se adentra en el corazón mismo de la cubanidad». Los autores y los textos en los que se basa el espectáculo son: Fernando Ortiz: Estudios Etnosociológicos; José Martí: Obras Escogidas; Severo Sarduy: Big Bang; Reinaldo Arenas: Leprosorio; Lorelis Amores: Décimas; y Julio Alexis Torres: Cartas a Eduardo.
} 
de aprehender totalmente; la identidad, ubicada afuera de la realidad simbólica construida, se encuentra en el ámbito de lo real y es allí donde se produce el encuentro con «lo político». En tal sentido, la propuesta cubana pone en escena, mediante la evidencia la falla del sistema lingüístico, lo real como límite de la representación simbólica, como la resistencia a la simbolización tal como aparece en el nivel de la construcción teatral.

La representación se vale de la simbolización que, necesaria e inevitablemente, excluye elementos. Es irremediable que también en la lectura del espectáculo tengamos que sacrificar algo, y aceptar la exclusión de aspectos que con seguridad son parte del significado. Dicho de otro modo, para lograr un significante que hable del producto, tenemos que sacrificar el significado. Propongo entonces, siguiendo a Grüner, leer el espectáculo mediante una «ficción operativa» entendida no como género discursivo sino como una forma de acercamiento a aquello que excede la capacidad de simbolización, pero que sin embargo, la determina en un choque perpetuo e irreconciliable entre el discurso teatral y algo del orden de lo real (2002: 97). Por ello, la «ficción operativa» que realizo para la lectura de Visiones de la cubanosofía no pretende agotar todos los aspectos ni hacer una lectura totalizadora, es más bien una aproximación con una lectura realizada con una intencionalidad política. ${ }^{7}$

En este trabajo me esforzaré en localizar los encuentros traumáticos con lo real que alteran o interrumpen las formas ordinarias de simbolización tal como aparecen en la escena, para lograr sentir la presencia, a través de su ausencia de lo que podría ser la «identidad» cubana nunca agotada. Vuelve así a la memoria del espectador —en especial al espectador cubano- aquello olvidado: las innumerables construcciones discursivas en las que se ha visto reflejado y con las que se ha identificado; los discursos culturales cubanos, que proponían diversas formas de «cubanidad» y que correspondían, a una «realidad construida» simbólicamente, sufriendo por tanto la misma falla radical de la insuficiencia del sistema lingüístico. Para leer la puesta y tratar de alcanzar alguna comprensión de ella, es necesario poner énfasis en la aparición de la paradoja, la inconsistencia aparente entre los fragmentos escénicos, la incompletitud y las fallas de simbolización en las que se vislumbra lo real, lo indecible.

Visiones de la cubanosofía se hilvana en varios niveles que corren paralelos y que se apoyan mutuamente: la gestualidad, el sonido, la palabra y el modo de su alocución. El movimiento ascendente y descendente de los personajes y la construcción del escenario con tres niveles de andamios de los que ellos suben y bajan, con un ritmo agresivo pero siempre parsimonioso, tienen papel importante en su lectura y se complementan para dar un resultado que golpea con fuerza al público, hecho que notamos cuando llega el oscuro final y a éste le cuesta romper el silencio con el aplauso.

En su búsqueda de la identidad la propuesta cubana recorre diversos momentos de la historia y los particulares modos que han pretendido captarla: la belleza de los nativos, la naturaleza exuberante, la música africana y europea, la literatura, la utopía revolucionaria fracasada y el exilio y lo que en la escena aparece como la desaparición misma de la isla. Vemos la Cuba cristiana, la Cuba yoruba y la Cuba socialista; la Cuba literaria y la Cuba conquistada y oprimida por el imperio de turno.

\footnotetext{
En la interpretación teatral, el punto nodal, indispensable para hacer una lectura que atraviese en línea horizontal los fragmentos, puede identificarse con la idea fundamental que guía toda la propuesta y que está relacionada con el juego de hegemonía, ideología y preferencias. No existe pues ninguna interpretación «necesaria» y tampoco una que sea «suficiente».
} 
Este recorrido que empieza en la conquista y termina con la contemporaneidad, está también sugerido en la música, que marca la división entre la Cuba europea y cristiana: música clásica cubana del siglo XVII (interpretada por el grupo Ars Longa, con acordes litúrgicos, escrita por Esteban Salas: Una noticia alegre, Popule Meus, Ave María Stella y Sabatto Santo), y la Cuba de herencia africana en la que predomina la percusión: $A$ Chano Pozo, San Pascual Bailón, el toque de palos y la música de Roberto Fonseca.

\section{LO REAL: FORMA DE «NECIA EXTERIORIDAD»8}

La realidad escénica es - como la realidad política y toda otra realidad-constituida en primer lugar en el nivel simbólico mediante el lenguaje y luego apoyada por la fantasía. Fantasía que puede consistir en el intento de representar una sociedad armónica ocultando la falla real, tal como lo hace la comedia, ${ }^{9}$ o la fantasía de intentar traer lo real a la escena y hacer presente, valiéndose de recursos escénicos, aquello que es inaprensible. Situación que no deja de ser paradojal puesto que en este caso la fantasía consiste en traer a la escena lo real, es decir negarse a encubrirlo por medio de la construcción fantástica, pero sabemos de antemano que esto último es también, en sí mismo, una fantasía.

Así como la realidad adquiere sentido sólo con lo real que la excede - en contra del constructivismo social que afirma que todo termina en la realidad construida-, el teatro o la «realidad escénica» tiene sentido solamente si tomamos en cuenta «lo político» entendido como una particular modalidad de lo real, ${ }^{10}$ situado fuera de la realidad - política a o teatral- construida (Stavrakakis, 2005: 72). Lo político no es el referente de la construcción discursiva o teatral, sino justamente aquello que la disloca desde adentro y que se muestra en elementos fragmentadores y perturbadores. Es el elemento que interactúa con lo imaginario y lo simbólico mediante la disrupción de las certezas que articulamos a través de ellos; es aquello que no puede ser simbolizado, lo imposible; sin embargo, su ausencia, la falta constitutiva del significado, sí puede ser fuente de simbolización. Esta falta constituye algo crucial para la significación y en este caso para la lectura que propongo para Visiones de la cubanosofía. ${ }^{11}$

\footnotetext{
8 Véase Foucault, 1989: 323.

- Un ejemplo de esto último, es el espectáculo El pelele de La Banda de la Risa (Argentina), basado en el sainete dirigido y adaptado por Claudio Gallardou de El señor Badanas de Carlos Arniches (1930). En él se representa la contradicción del neoliberalismo — en ese entonces en gran apogeo en la Argentina de Menementre la razón civilizadora del modelo económico y la exigencia del respeto a los derechos humanos de los trabajadores. Sin embargo, termina en una falsa reconciliación con un final feliz digno de Hollywood, en el que lo que parece afirmarse es la necesidad inevitable de «eliminar» o someter a ciertos sectores de la población para la imposición y mantenimiento del modelo. Este es un final de comedia que esconde la falla fundamental que está por debajo de toda la propuesta, una sutura artificial y falsa que pretende cerrar el problema de manera completa (Proaño, 2007: 153).

10 La ausencia de lo real tiene que ser compensada si la significación va a adquirir alguna coherencia. Esta ausencia causa la transferencia del significado que emerge en su dimensión imaginaria. Hay sin embargo una dimensión más en este juego del significante. La transferencia del significado imaginario que es el resultado de un interjuego entre significantes.

" Es imposible no pensar en la «cosa en sí» de Kant, aquello que está detrás de todo el mundo fenoménico pero que es inalcanzable y que, en última instancia, nunca podremos conocer, pero que sin embargo es la fuente del conocimiento.
} 
La construcción teatral, mediante diversos procedimientos permite vislumbrar la presencia de aquello que rompe la imagen idealizada de una comprensión perfecta y armónica de lo que es el ser cubano. Para descubrirlo es necesario mirar afuera de la escena, al contexto histórico y político en el que el imaginario se origina. Sólo así vislumbramos perceptivamente y sin certeza, la aparición de una interrupción o una ruptura de sentido (Žižek, 1991). ${ }^{12}$

El programa de mano de Visiones de la cubanosofía subraya la imposibilidad de captar simbólicamente lo real cuando afirma que la intención del grupo es «Saber de Cuba que quizás, ‘en algún lugar de la memoria del cuerpo', usted descubra que también sabe» (Programa de mano) (el énfasis en la cita es mío). Es sólo a nivel de la sensibilidad que entrevemos este saber, que al final se nos escapa. Lo real, lo irrepresentable, aparece y desaparece en la intersección con la realidad teatral construida mediante el lenguaje teatral (Stavrakakis, 2005: 44). Al respecto, las palabras de Nara Mansur ${ }^{13}$ (2006) confirman la necesidad de la búsqueda ya no sólo del grupo productor del espectáculo sino de todos los cubanos:

... Visiones de la Cubanosofía utiliza[ndo] la palabra deseo como eje de la composición. Deseo saber de Cuba. Deseo saber de los cubanos. Deseo saber de mí. La parte y el todo. La sensación se parece al malestar (¿de la cultura?), al malentendido, a una cierta (por verdadera) ansiedad de aspirar a la revelación (87).

Se espera que esta «revelación» o emergencia del significado aparezca como el resultado del interjuego entre los significantes y los vacíos causados por la irrupción de lo real, por las rupturas y las negaciones que emergen en la escena. Es el predominio del significante teatral lo que produce el significado imaginario en forma de construcciones sucesivas de una supuesta identidad cubana, y que cubre el significado como real: una identidad genuina que el espectáculo dice buscar, ese «saber de Cuba" que al final no se encuentra más que en la forma de una pregunta final.

\section{LAS IDENTIFICACIONES O EL REFLEJO DEL ESPEJO}

Frente a la propuesta del grupo cubano, somos testigos de las limitaciones del lenguaje escénico. Estamos atrapados en el lenguaje que, por insuficiencia, no puede capturar ni la totalidad ni la singularidad en forma completa. La simbolización introduce la falta, y hace el alcance de la identidad cubana total, completamente imposible. Aparecen entonces una serie de identificaciones que constituyen el sujeto construido en base a ellas.

Según Laplanche y Pontalis (1988), la identificación se refiere a un proceso por el cual el sujeto asimila un aspecto, propiedad o atributo del otro y se transforma, total o de manera parcial de acuerdo al modelo provisto. Es mediante una serie de identifi-

\footnotetext{
$12 \quad$ En Dikeç, 2005: 172.

13 Nara Mansur, investigadora, teatrista y poeta cubana a la que debo el haber tenido la posibilidad de asistir a la función de El Ciervo Encantado en mayo del 2006, realizada en el Instituto Superior de Arte en La Habana.
} 
caciones que la personalidad se constituye y se hace específica (citado en Savrakakis: 29-30). Este concepto de identificación es muy relevante para el análisis social y político de Visiones de la cubanosofía. El espectáculo, mirado bajo esta lupa revela la búsqueda de la identidad en el espacio teatral, mediante el despliegue de sucesivas identificaciones escenificadas en forma de fragmentos; ellos demuestran la asimilación del concepto de «cubanidad» a propiedades que los discursos culturales, cubanos o no, han desplegado a través de la historia. Los fragmentos escénicos descubren la falsedad de las identificaciones desplegadas.

Visiones de la cubanosofía nos habla entonces de lo que Cuba no es, inscribe la negación dentro de la representación teatral y revela la distancia entre la representación y lo real, en una construcción simbólica que incluye el reconocimiento de los límites de la simbolización. Ante la percepción del colapso temporal de todos los puntos de identificación, y la aparición constante de irrupciones dislocantes de la escena, la puesta genera un clima de angustia que en Visiones de la cubanosofía se revela en la risa incómoda generada en los espectadores y que no es otra cosa que la forma audible de la angustia.

Esto sucede por ejemplo en la escena de Ochún en la cual aparece el contraste entre la palabra, que enumera una sucesión de identificaciones adjudicadas a Cuba, y la gestualidad corporal. Si bien la incongruencia grotesca que surge del choque del discurso verbal con la gestualidad escénica causa la risa incómoda del público, mucho más importante es señalar que dicha incomodidad se debe a la sensación de que esta incongruencia es el resultado de la evidencia escénica de la insuficiencia del lenguaje. Esto se vislumbra en la escena mediante la exhibición explícita de la no correspondencia entre las palabras - lo simbólico- - y la fantasía teatral, intento de captar la identidad cubana. La incongruencia causa la emergencia, de lo que no se puede expresar, apenas sospechado, que irrumpe en la escena y disloca la identificación de turno con que la fantasía ha intentado construir la identificación con todo aquello que Ochún menciona. Aparece el límite de la escena teatral que nos habla de la imposibilidad de representar lingüísticamente lo que está más allá del lenguaje. Es aquí donde emerge lo siniestro, el encuentro con lo extraño; aparece la sensación de que allí hay algo más de lo que es imposible hablar y con ello, el consecuente nerviosismo de los espectadores. Imaginemos la escena.

Las didascalias describen a Ochún que viene en cuatro patas emitiendo sonidos guturales desde debajo de los andamios, mientras se dirige a los espectadores. Vemos a la diosa Lucumí, en un cuerpo vestido en harapos, como una vieja sin dientes, y un esqueleto con un agujero profundo en la boca. Es un esqueleto maltrecho que se convulsiona con movimientos torpes y que, cuando pretende hacer un gesto de triunfo y levanta el brazo al final del parlamento, a la incongruencia entre el discurso escénico y el discurso verbal, se suma lo ridículo del gesto. Dice:
Ahhhhhhhhh!!!
Ahhhhhhhhh!!!
Ahhhhhhhhh!!!
Ahhhhhhhhh!!!
La reina de la fritangaaaaa,
La reina de la rumba,
No quiero cuento ni bobería,
La rumba es cu-ba-naaa,
La llave del golfo,
La tormenta del Caribeeee
La perla del Edén, 
La única.....

La reina del Carnaval!!... (Visiones de la cubanosofía) ${ }^{14}$

¿Qué representa esta figura contradictoria para la sensibilidad cubana? Veamos:

En la máscara de la mujer con la guataca (Mariela Brito es la actriz que la representa) veo a la muerte... la muerte que acecha, el peligro que viene y la muerte, muerte, de cuerpo presente... veo a la campesina de la famosa estatua que identificó a la Revolución Rusa, a Francisca, la metáfora rural creada por el narrador Onelio Jorge Cardoso... «veo el arquetipo saltando» en pedazos también... y la queja larga y monocorde en una onomatopeya que se oye a sí misma, una palabra que se alarga en lo sensorial más allá de los «significados silenciados» (el énfasis es mío) (Mansur, 2006: 87).

Aunque es imposible presentar la identidad/lo real en la escena ésta enmarca la imposibilidad que surge del intento de simbolización. Sin embargo, inferimos su presencia por los efectos y la resistencia que aparece en el nivel de la representación de la que parece estar consciente el discurso teatral. Según Mansur (2006), «El espectáculo organiza un discurso conocido y lo balbucea, se niega a interpretar una historia, se niega a interpretar la Historia. Ellos tampoco representan. Hay un desdibujado rol que más allá del artificio...» (87). Desdibujado rol que a la vez garabatea algo que no se encuentra, que no se puede expresar. Creo que el grupo no sólo reconoce, en el texto mismo, la imposibilidad de interpretar aquellos «significados silenciados» de los que habla Mansur:

... no son como pudieron haber sido, viven entre jabas y jabucos. ¿Qué vine a hacer aquí, que no recuerdo? Ciento once mil, ciento once kilómetros cuadrados de un semipalmar, de un semidesierto, un semilamento. Todo eso lo vi, pero naturalmente si usted no lo vio, «¿cómo puedo mostrárselo?» (El énfasis es mío) (Visiones de la cubanosofía).

\section{EN BUSCA DE «OTRO» LENGUAJE}

El lenguaje teatral es un sistema estructurado de significantes — verbo, sonido, luz, gestualidad, espacio y movimiento- que adquieren su valor en tanto diferentes de otros elementos del sistema y cuyo sentido varía según la posición en la estructura, aspecto que, tomado en cuenta, posibilita la lectura de la puesta en escena.

Visiones de la Cubanosofía intenta resistir al poder, se niega a usar el lenguaje de la ley, trata de escapar del lenguaje verbal estructurado, para expresar la conciencia de la insuficiencia del mismo y encontrar la respuesta que se busca para intentar presentarla en la escena. De manera significativa, al comienzo de los parlamentos de las dos deidades, la cristiana y la Yoruba, se escenifica la dificultad de articular el lenguaje y lo que podría ser el intento de encontrar un lenguaje alternativo. La Virgen de la Caridad que, iluminada por un cenital blanco, ocupa el centro y la parte superior del escenario, mueve la boca — cavidad profunda y roja- durante varios minutos logrando, solamente después

\footnotetext{
14 Todos los textos del espectáculo están tomados del manuscrito enviado por vía electrónica gracias a la generosidad de Nelda Castillo.
} 
de mucho esfuerzo, emitir balbuceos, sonidos extraños y ruidos respiratorios; sólo al final logra articular el lenguaje pronunciado con dificultad y mezclado aún con sonidos ininteligibles. Por otra parte, Ochún — la orisha lucumí que corresponde a la Virgen del Cobre - se arrastra y se yergue con mucha dificultad mientras inicia su parlamento, no emitiendo más que sonidos y ruidos. Mantiene siempre las rodillas dobladas, posición que junto con los prolongados gemidos previos a las palabras, sugiere quizá el esfuerzo por parir un lenguaje diferente o romper sus limitaciones. Sin embargo, al final tanto la Virgen como Ochún tienen que recurrir al lenguaje estructurado, a lo simbólico. No hay escapatoria posible, la escena está atrapada en el lenguaje.

El lenguaje teatral en el que se articula la propuesta descansa en la metáfora y la metonimia. Por medio de la metáfora (condensación y sustitución) nos centramos en el análisis de cada fragmento en sí mismo, es decir en los posibles significados que surgen en el eje paradigmático sincrónico del lenguaje. Recurrimos en la lectura, a la metonimia para observar el deslizamiento del significado en la cadena de significantes y así dilucidar el proceso de significación que produce un sentido; realizamos la conexión de escena a escena en un eje sintagmático diacrónico del lenguaje, lo que se traduce, en este caso, en la lectura de cada fragmento de la puesta, en relación a todos los demás. Estos dos recursos se complementan para el análisis de la experiencia teatral, que debe recurrir a la referencia estructural para buscar una interpretación de un posible sentido de la puesta en escena.

Es necesario entonces, encontrar el significante que haga las veces de punto nodal sin el cual la escena sería sólo una suma de imágenes o símbolos aislados; es indispensable encontrar el significante que atraviese todos los fragmentos. En este caso, el punto nodal es, tal como el grupo lo declara, la búsqueda de la identidad cubana, significante que para el deslizamiento de sentido. Es el quilting point que fija el sentido en toda la cadena de significantes, el punto de convergencia que posibilita el análisis del discurso teatral (Lacan III: 267 en Stavrakakis: 60).

Visiones de la cubanosofía escenifica un entretejido de metáforas, que parecen disconexas y marcan un posible significado de la cubanidad. Sin embargo, leídas en contexto y unidas en la cadena de significantes, producen un deslizamiento de sentido que transmite la imposibilidad lingüística de captarla, pues se revelan sólo como sucesivas identificaciones que nunca alcanzan la identidad total.

Al respecto, la primera escena del espectáculo parece constituir una especie de alegoría sobre toda la propuesta: ésta se inicia en una completa oscuridad interrumpida por el sonido de un timbre al que se suma música clásica renacentista. Poco a poco y de modo muy tenue aparece una luz blanca en el fondo del escenario donde se distingue una figura, cuya silueta, que apenas adivinamos en la escena, emite los sonidos de una respiración dificultosa. Este inicio parece adelantar el carácter críptico de la propuesta y la imposibilidad de expresar en la escena lo que se busca.

En el eje sincrónico, las imágenes metafóricas de cada fragmento, leídas por separado, aluden a la exterioridad de la escena que despliega los particulares modos en que las sucesivas identificaciones han ofrecido definiciones de la cubanidad. Visiones de la cubanosofía se inicia con la Virgen del Cobre barbuda — síntesis entre liberación y cristianismo al comienzo de la revolución (González) ${ }^{15}$ —; José Martí y Ochún compartiendo el mismo espacio — el cristianismo y la santería-; El Decimista — con una significación

15 «También aquellos barbudos que bajaban de las lomas en los primeros días de 1959, lucían en sus pechos la medalla de la Virgen y se proclamaban sus hijos». González insta a que «nunca más sustituyamos su imagen por falsas reliquias de falsos mesías» <www.pdc-cuba.com/Boletinagosto.pdf>. 
ambigua en tanto parece aludir a la represión pero que puede ser también la posibilidad de su evasión ${ }^{16}$. Lezama, ${ }^{17}$ mendigo — desposeído-entra al escenario arrastrando bolsas llenas de plásticos vacíos, y que para escribir tras las rejas, saca sus brazos y la máquina de escribir, fuera del espacio central de la escena; ${ }^{18}$ la Ciudad, con movimientos que pretenden ser elegantes y un vestuario europeo, que adquiere movimiento/vida con cada golpe del teclado de Lezama, metáfora de la escritura como dadora de vida y memoria; el Conquistador que presta la versión de la cubanidad desde la mirada del otro, hecho que se acentúa con su caracterización escénica que sintetiza, en el vestuario y el maquillaje, la historia de la Cuba dominada por los sucesivos imperios: lleva peluca naranja - lo no cubano - traje de encaje blanco y dorado, cercano a la moda europea del siglo XVII, gafas de sol y cámara fotográfica al estilo norteamericano. Su discurso empieza con la descripción de los nativos originales — «Plumas de flamenco, espinas de pargo, semillas de aguacate, tomate, maní. Los nativos son dulces y melancólicous, andan desnudos?!!!, tienen la piel del colouur de la carne del membrillo» (manuscrito de Visiones de cubanosofía) - y termina con el comentario contemporáneo de la cantidad de carne de puerco que es posible comprar por unos pocos dólares. Sigue el fragmento del exilio como final de la vida, junto con Lázaro - Babalúaye, Orisha Lucumi de la religión Yoruba- que ha muerto llevándose con él, la posibilidad de vida. Casi al final del recorrido el pescador lee un texto que da existencia escénica, valiéndose de las palabras de Severo Sarduy, a un "agujero negro", resultado de la deformación del espacio por la cual toda materia es capturada y no puede escapar. Este es el momento distópico culminante de la propuesta de Castillo, en la que aparecen «residuos de personas, moralejas tristes, seres carcomidos, de vuelta también de una primera muerte» y ante la que es posible preguntarse junto con Mansur (2006): "¿Qué son estas criaturas terriblemente vivas que generan desde la escena la imagen de una morgue, el horror de los condenados, la enfermedad, los apestados...?» (89).

En la escena siguiente aparece Martí, «el conductor de la energía... El [que] escudriña estas 〈visiones»» (Mansur 2006: 88). Él está sentado en el andamio superior de la escena y al lado de la Virgen de la Caridad del Cobre, mirando al público con el sombrero mambí de cuya estrella roja emana la única luz que permanecerá en la escena por algunos segundos cuando llegue el oscuro final. Si recordamos que los mambises eran los campesinos revolucionarios que lucharon por la independencia de Cuba; que la Virgen de la Caridad fue proclamada por primera vez en El Cobre donde se hizo efectiva la libertad de los esclavos y que además el 12 de agosto de 1868 se lleva a cabo la declaración Mambisa de

\footnotetext{
16 Recordemos que en 1959 la décima como forma estrófica contó con el apoyo del gobierno revolucionario. Sin embargo, las décimas recitadas sugieren la posibilidad de hablar de lo prohibido, siempre que mantengamos la forma y que el discurso esté cubierto por la ambigüedad metafórica.

17 De la décima se pasa a la poesía hermética de Lezama Lima. Su posición escénica atrás del andamio/rejas, metaforiza ambiguamente tanto el hermetismo de su escritura cuanto el aislamiento a que fue sometido los últimos años de su vida. En este sentido es posible leer la metáfora del hombre escribiendo ya fuera del espacio central de la escena, librado de su entorno mediante la poesía, creando su propia resurrección a la muerte en vida a que había sido condenado. Ante la realidad, presente en la escena de la ciudad harapienta, él escapa mediante la escritura.

18 Esta imagen escénica tiene correlación con uno de los topos de la poesía de Lezama: el tokonoma, como se ve en el siguiente fragmento: "Me voy reduciendo/soy un punto que desaparece y vuelve/ y quepo entero en el tokonoma. / Me hago invisible / y en reverso recobro mi cuerpo... Pero el vacío es calmoso/lo podemos atraer con un hilo/ e inaugurarlo en la insignificancia.... Me duermo / en el tokonoma /evaporo el otro que sigue caminando. («El pabellón del vacío», Fragmentos a su Imán, 1978.
} 
la independencia del pueblo cubano a sus pies, es posible leer, en el discurso teatral, la presencia de una posible apertura hacia el futuro, una apertura que contiene además, en sí misma una advertencia, pues tal como afirma Orizondo (2007), «la gente sale enferma con la luz roja en los ojos ... una luz que no alcanza para saber quién soy». La Virgen ha quedado despojada de la barba, que la unía al inicio de la puesta, con los ideales de la revolución, ${ }^{19}$ en el nivel superior donde, desde el final de la primera escena ha sido mudo testigo del recorrido histórico, de la descomposición, de las múltiples preguntas y las negaciones que la escena nos plantea. La imagen de Martí se ha despegado ahora de la realidad revolucionaria escenificada en el nivel más bajo de los andamios.

Los niveles espaciales de la escena parecen separar la Cuba de la realidad política y social vinculada con la lectura distópica, del espacio superior - ¿acaso el de la esperanza? - ocupado ahora solamente por la Virgen del Cobre, despojada ahora de la barba, y Martí. Esto sugiere la posibilidad de un cambio, quizá una revolución que esta vez venga desde los ideales de Martí, junto a la Virgen del Cobre, unidos a la lucha mambí por la independencia cubana. ${ }^{20}$ Visiones de la cubanosofía mostraría, en este caso en su estructura, lo que Roig (1995) ha llamado «la función utópica de su discurso» en cuanto éste ofrecería una posibilidad abierta hacia el futuro. Visiones de la cubanosofía aunque no se propone ninguna utopía concreta, parece abrir la posibilidad de un futuro deseado diferente.

La pluralidad de metáforas se hilvana gracias al significante nodal, ${ }^{21}$ en este caso, la búsqueda de la identidad, que da sentido al paso de un fragmento al siguiente y permite una lectura diacrónica de la propuesta. La sucesión escénica de fragmentos sin otro marco que la presencia muda y vigilante de la Virgen de la Caridad, desmiente, valiéndose del lenguaje escénico, que en algunas de estas opciones se haya encontrado la respuesta a la pregunta por la cubanidad. Cada fragmento no es sino la puesta en escena de alguna identificación y de la correspondiente negación de aquello que en el momento pertinente aspiraba a definir la cubanidad.

En tanto el ser cubano no puede ser comprendido en su totalidad, la identidad no es aprehensible. Sin embargo, de algún modo «eso» (la identidad ubicada en el ámbito del

\footnotetext{
19 Según González «También aquellos barbudos que bajaban de las lomas en los primeros días de 1959 , lucían en sus pechos la medalla de la virgen y se proclamaban sus hijos. Orizondo por su parte, habla de «un poder vestido de divinidad» y alude a la conexión entre el Papa y el padre cuando dice «juegan con mi barba cada vez más negra y larga interminable».

20 Según el historiador Cubano, Carlos Márques Sterling, la palabra «Mambí» es de origen Afro-Antillano y se aplicaba a los revolucionarios de Cuba y Santo Domingo (ahora la República Dominicana) en el Siglo XIX. Según el escritor de ficción Elmore Leonard, en su novela de aventuras Cuba Libre, la palabra Mambí viene de Eutimio Mambí, un líder que peleó contra los españoles en Santo Domingo 50 años antes. Los soldados españoles, notando las tácticas similares en el uso del machete de los revolucionarios cubanos, comenzaron a referirse a ellos como los «hombres de Mambí», lo que luego se acortó con el uso a «Mambís» o «Mambíses». En Cuba la palabra "Mambí» se reserva para señalar a los patrióticos soldados que pelearon en contra de España en la Guerra de Independencia 1895-1898. Sitio web de La Jiribilla.

21 Es necesario encontrar el significante que hace las veces de punto nodal sin el cual la escena es sólo una suma de imágenes o símbolos aislados, en el teatro tenemos que encontrar el significante que atraviesa todos los fragmentos y que en este caso, es declaradamente, la identidad cubana. En la interpretación teatral, el punto nodal puede quizá identificarse con la idea fundamental que guía toda la propuesta y que está relacionada con el juego de hegemonía, ideología y preferencias del que hemos hablado. No existe pues ninguna interpretación «necesaria» y tampoco una que sea «suficiente» pues aunque se intente integrar dentro de la interpretación todos los elementos posibles, siempre habrá elementos que queden fuera de la lectura y no serán, en ese sentido transformados en momentos del discurso crítico (Stavrakakis, 2005: 80).
} 
real inalcanzable) que no es posible definir ni conocer, disloca la realidad teatral desde adentro y niega la exactitud de las identificaciones hechas a través de la historia. La identidad, "lo que el ser cubano es», no es posible de expresar pero está presente sin embargo en la puesta, en tanto enmarca la imposibilidad de agotar su sentido, de alcanzar una conceptualización completa. Esto es lo que se vislumbra en Visiones de la cubanosofía, gracias a la irrupción de las incongruencias/síntomas que, mediante la parodia, la ironía, el lenguaje corporal y la escenificación de la insuficiencia del lenguaje, dislocan la escena. Una escena en la que constantemente aparecen las inconsistencias, como una afirmación de la imposibilidad de captar el ser cubano de manera total y acabada. La negación de las identificaciones ejemplificada en la escena: Lezama Lima, el poeta cubano, escenificado como un desposeído que arrastra bolsas de plástico, la ciudad - La Habana - viste una elegancia propia del siglo XVIII pero en andrajos y finalmente, Martí, el héroe nacional, "crucificado» en los andamios, junto con Ochún que se ríe de sí misma.

La escena aparece como un intento de exhibir el juego entre la posibilidad y la imposibilidad que gobierna el campo de la construcción, no solamente teatral. Pone en el espacio teatral, alternadamente, la representación y su fracaso, la articulación y la dislocación y finalmente la realidad falsificadora, siempre limitada por lo real. Por ello, en muchos momentos en la propuesta de El Ciervo Encantado aparece lo siniestro, lo que está más allá del lenguaje, el encuentro con lo extraño.

\section{CONCLUSIÓN}

Cubanosofía es un magnífico ejemplo de la negación del isomorfismo entre significante y significado en tanto los primeros se re-significan gracias al modo en que están tejidos en la estructura teatral. Surge el significado en su dimensión imaginaria - la creación teatral- como resultado de un inter-juego entre significantes. Lo simbólico entonces determina la significación y con la ayuda de los recursos escénicos intenta descubrir aquello que es imposible de aprehender en su completitud. El espectáculo trata de acercarse a la identidad cubana, negando las sucesivas identificaciones que han creado un significado imaginario que cubre la ausencia del significado completo de la misma.

La escena crea un nuevo significado que rebasa la representación: la imposibilidad de alcanzar una identidad completa, al mismo tiempo que afirma la falsedad de las identificaciones que han desfilado en el espacio teatral, revelando, muchas de ellas, intereses hegemónicos del poder, intereses que varían según la historia y que comienzan con el Imperio Español, pasan por la Revolución cubana y terminan con los intereses económicos y políticos norteamericanos.

Ante la imposibilidad de captar lo que está afuera del lenguaje, el Ciervo Encantado intenta darnos un viso de comprensión logrado sólo de modo perceptivo, a través del cuerpo. A través de la escenificación de las sucesivas identificaciones y mediante los recursos escénicos que las niegan y las critican, el espectador intuye aquello que se encuentra afuera de la realidad política y escénica. Por otra parte esta búsqueda destinada al fracaso desde el comienzo, constituye la tragedia del drama distópico. Por una parte, esta tragedia consiste en la constatación de la imposibilidad lingüística de captar aquello que se busca y por otra, la denuncia escénica parece hablar del fracaso del proceso revolucionario que cual «un hueco negro» absorbe y captura toda la materia que no puede escapar. Escuchemos al Pescador cuando lee un grueso libro: 
Tradicionalmente, la deformación del espacio alrededor de un cuerpo masivo se compara con la de una membrana de caucho horizontal bajo el peso de una bola. Cuando un derrumbe gravitacional se produce, asistimos al nacimiento de un verdadero hueco en el espacio tiempo, hueco que devora totalmente la materia del objeto. Es la geometría misma del espacio tiempo lo que, en una cierta zona, se ve arrastrada por el derrumbe. Toda materia, todo rayo proyectado a partir de esa zona es capturado irreversiblemente y no puede escapar. De modo que del objeto derrumbado no puede llegarnos ninguna señal. Queda pues explicado por qué a esos objetos celestes que han llegado a fases extremas de su derrumbe gravitacional se les ha llamado «huecos negros», huecos negros (Manuscrito enviado por la directora).

Lecciones de cubanosofia explota al máximo las posibilidades polisémicas de la escena desechando todo sentido directo; con densidad metafórica y rupturas sintácticas entre los fragmentos sucesivos, parece tocar el absurdo hasta que descubrimos que todos los retazos se unen en la búsqueda de la respuesta a la pregunta inicial. Al mismo tiempo, el final de la propuesta echa luz, gracias a los símbolos y a la escena, sobre una posibilidad, una tenue esperanza — como la luz del final— que todavía queda abierta y que proviene del sombrero mambí que lleva Martí, quizá una leve sugerencia de que, desde la perspectiva de El Ciervo Encantado, su figura es lo más cercano a la cubanidad.

Toda la propuesta se teje en una dialéctica de la imposibilidad, en un horizonte ontológico que articula la realidad política; entre el orden y el desorden, entre lo político y la política, entre las identificaciones y la identidad; se revela al final sólo como una pregunta más que parece indagar la posibilidad de una revolución propiamente cubana, en la que se expresa el deseo —otra vez, el deseo- de que Cuba encuentre identificaciones más cercanas al sentir cubano.

El Ciervo Encantado toma posición dentro de lo que sería una política de la identidad en la búsqueda de la superación de las identificaciones sucesivas adoptadas o adjudicadas al «ser» cubano. La falla fundamental del lenguaje — no sólo teatral—, su insuficiencia, es el lugar vacío en donde tiene lugar esta política y desde el cual Visiones de la cubanosofía construye su propuesta. Al hacerlo, desenmascara en la escena teatral la radical dependencia de tales identificaciones con las construcciones discursivas que la historia, la política - tanto interna como internacional junto con su juego de intereses-y la realidad social le ha ofrecido en cada momento histórico, espejo en el que el ciudadano cubano se ha mirado inevitablemente. La propuesta es un gesto no sólo teatral, sino también social y político que reconoce el límite fundamental de la representación, ya sea esta lingüística, teatral o política, haciendo visible esta falla y reconociéndola como insuperable.

Por supuesto, estoy consciente de que así como es imposible crear una realidad teatral sin exclusión es también imposible construir un discurso crítico totalizador. Pero creo posible afirmar que Visiones de la cubanosofía, en tanto teatro de lo político, no es el espacio utópico en el que el desorden se transforme en orden, la heterogeneidad en homogeneidad o que proponga un proyecto utópico futuro. No aspira tampoco a una catarsis que elimine la ansiedad y la pérdida; todo lo contrario, pone el acento en la dislocación y en la tragedia del deseo siempre presente, de una armonía nunca alcanzada.

Parodiándose a sí mismo y lleno de ironía y sarcasmo el discurso teatral, tejido en una dialéctica de la imposibilidad, logra un mensaje buscadamente crítico que penetra en lo que se ha entendido por la cubanidad para, en una mezcla de un tono distópico y una búsqueda existencial, preguntarse por el ser cubano y la carencia de un destino claro para el país. 


\section{REFERENCIAS}

Castillo, Nelda. (2005). Visiones de la cubanosofía. Manuscrito no publicado.

De Aguila, Rafael. (2006). Las inefables versiones del ciervo. Tablas/Alarcos, Casa editorial. Obtenido el 10 de junio de 2008 desde <http://www.tablasalarcos.cult.cu/ oficiocritica/2006/critica22_06.htm>

Dikeç, Mustafa. (2005). Space, politics and the political. Environment and Planning D: Society and Space 23.2: 159-316.

Foucault, Michel. (1989). The Order of Things. Trad. A. sheridan-Smith, Londres: Routledge.

González, Oscar Mario. A los pies de la virgen. Obtenido el 7 de septiembre de 2007 desde <www.pdc-cuba.com/Boletinagosto.pdf>

Grüner, Eduardo (2002). El fin de las pequeñas historias. De los estudios culturales al retorno (imposible) de lo trágico. Buenos Aires: Paidós.

Laplanche, Jean y Jean Bertrand Pontalis. (1988). The Language of Psychoanalysis, trans. D. Nicholson-Smith, Londres: The Institute of Psychoanalysis/Karnak Books.

Leyva, Leyva. (2005). Roberto Manzano: Todavía sigo caminos riesgosos. Cuba Literaria. Portal de Literatura cubana. Entrevista obtenida el 22 de junio de 2005 desde $<w w w$. cubaliteararia.com/delacuba/ficha.php?Id-2864>

Lezama Lima, José. (1978). Fragmentos a su Imán. México, DF: Editorial Era.

Lozada, Jesús. (2008). La tía Lucila, el laúd y la controversia de siglos. Obtenido el 3 de mayo <http://www.lajiribilla.cu/2008/n363_04/363_20.html>

Mansur, Nara. (2006). Una lección de cubanosofía. Tablas. Nº. 1, ene.-mar (87-89).

Orizondo, Rogelio. (2007). Visiones de la cubanosofía, obtenido el 2 de agosto de 2008 en <www.tablasalarcos.cult.cu/oficiocritica/2007/critica026.htm>

Proaño Gómez, Lola. (2007). Poéticas de la globalización en el teatro latinoamericano. Irving, California: Gestos.

Programa de mano. (2006). Visiones de la cubanosofía. El Ciervo Encantado. Instituto Superior de Arte: La Habana.

Ranciere, Jacques. (2001). Ten Theses On Politics. Theory and Event 5.3. Obtenido desde <www.muse.jhu.edu/journals/theory_and_event/v005/ranciere.html>

Roig, Arturo. (1995). Proceso civilizatorio y ejercicio utópico en Nuestra América. San Juan: Editorial Fundación Universitaria de San Juan.

Stavrakakis, Yannis. (2005). Lacan \& the Political. Nueva York: Routledge.

Sitio Web de La Jiribilla, Cuba. (2007). Datos interesantes sobre el ejército Mambí. Obtenido el 15 de octubre desde <http://www.cubagenweb.org/mil/mambi/e-trivia. htm\#mambi>

Žižek, Slavoj. (1991). For They Know What they Do. Enjoyment as a Political Factor. Londres: Verso.

Recepción: mayo de 2008

Aceptación: septiembre de 2008 